\title{
Polyetheretherketone (PEEK) Composites Reinforced with Fly Ash and Mica
}

\author{
M. Rahail Parvaiz ${ }^{1}$, Smita Mohanty ${ }^{1}$, Sanjay K. Nayak*¹ and P. A. Mahanwar ${ }^{2}$ \\ ${ }^{1}$ Laboratory for Advanced Research in Polymeric Materials, Central Institute of Plastics \\ Engineering \& Technology, Bhubaneswar- 751 024, India. \\ ${ }^{2}$ Department of Polymer Engineering and Technology, University Institute of Chemical \\ Technology, Matunga, Mumbai -400 019, India. \\ * Corresponding Author: larpmcipet@gmail.com
}

\begin{abstract}
Polyetheretherketone (PEEK) composites were developed using fly ash and mica as fillers. PEEK composites of 5-30 wt\% loading were compounded using twin screw extruder. Tensile strength, tensile modulus and flexural modulus increased with the incorporation of both the fillers in PEEK matrix. Tensile modulus of PEEK fly ash composites was found to be higher than PEEK mica composites. Charpy impact strength of PEEK mica composites improved drastically up to $15 \mathrm{wt} \%$ of filler but in PEEK fly ash composites charpy impact strength was decreased. The effect of fly ash and mica on the percentage crystallinity of PEEK composites was studied by using modulated differential scanning calorimeter (MDSC). Limiting oxygen index (LOI) of PEEK fly ash and mica composites also improved by $11 \%$ and $24 \%$ respectively than pure PEEK at $30 \mathrm{wt} \%$ loading respectively. The dynamic modulus of PEEK composites shows over 133\% increment at 100-250 ${ }^{\circ} \mathrm{C}$, indicating improvement of elevated temperature mechanical properties. Effects of filler on the morphology of PEEK composites have also been discussed.
\end{abstract}

Key Words: Polymer matrix composites, Fillers, Fly ash, Mica, SEM

\section{INTRODUCTION}

The reinforcing effect of mineral filler for polymers has been recognized after 1930s. Since the last three decades, improving the mechanical, electrical, thermal, optical and processing properties of polymer with the addition of filler material has become a very popular research interest. Polymer science and technology seek new routes to improve the performance of filled plastic materials while reducing their costs [1]. 
Polyetheretherketone (PEEK) is a high performance semicrystalline polymer having outstanding thermal stability, wear resistance, mechanical properties, and excellent resistance to chemicals. It has high melting $\left(\mathrm{T}_{\mathrm{m}}\right)$, glass transition $\left(\mathrm{T}_{\mathrm{g}}\right)$ and continuous service temperature. It can be processed by conventional methods such as injection molding, extrusion, compression molding and powder coating techniques. Therefore, PEEK and its composites have been reported for use in aerospace, automotive, structural, high temperature wiring, tribology, and biomedical applications [2-5].

Utilization of fly ash (FA) as an additive component in polymer composites has received increased attention recently, particularly for high volume applications for effective disposal of the material and reducing the overall cost of the composites. Fly ash is a waste material, obtained in huge quantities from thermal power plant as by-product of the burning of pulverized coal. It is a fine and powdery material. A microscopic view would reveal that the particles are essentially spherical. Fly ash has been used as spherical filler for the production of lightweight high strength concrete [6].

Mica is a plate like crystalline alumino-silicate and has been widely used as reinforcing filler in polymeric matrices due to its excellent mechanical electrical and thermal properties [7]. The commercial delamination of mica may be characterized as wet or dry according to whether the delamination is carried out in a dry state or water. Wet grinding preserves the natural luster and sheen of mica and is normally characterized by clean cut edges, high aspect ratios, smooth surface, and ability to disperse easily [8].

In this study, PEEK filled $0-30 \mathrm{wt} \%$ fly ash and mica composites were prepared by compression molding technique to investigate the effect of particle shape of filler on the mechanical, thermal properties such as limiting oxygen index, glass transition temperature $\left(\mathrm{T}_{\mathrm{g}}\right)$, crystallization temperature $\left(T_{c}\right)$, storage modulus $\left(E^{\prime}\right)$ and morphology of PEEK fly ash and mica composites were observed by using scanning electron microscopy.

\section{EXPERIMENTAL}

\subsection{Material}

Matrix material Polyetheretherketone (5300 grade) was obtained from M/s Gharda Chemicals, Ltd. Panoli, Gujarat, India. Fillers fly ash of particle size 44 micrometer was obtained from Kuradi thermal power plant, Nagpur India and mica (wet grinded) of particle size 44 micrometer was supplied by M/s Galaxy Corporation Pvt Ltd., Mumbai India. 


\subsection{Compounding}

Polyetheretherketone, mica and fly ash were predried at $100 \pm 5{ }^{\circ} \mathrm{C}$ for $8 \mathrm{hrs}$ prior to compounding. Fly ash and Mica (0-30 wt $\%)$ were added to Polyetheretherketone. The composites were prepared by using melt mixing technique using counter-rotating, twin screw extruder (RC 9000, Haake Germany) at L/D ratio of 20:1 and screw speed of $40 \mathrm{rpm}$. The temperature profiles in barrel were maintained from $200,250,320,340,360{ }^{\circ} \mathrm{C}$ from feed zone to die zone. The extrudates were water cooled at room temperature, cooled to room temperature and pelletized.

\subsection{Compression Molding}

The pelletized granules of PEEK, fly ash and mica composites were predried at $100 \pm 5{ }^{\circ} \mathrm{C}$ for 8 hrs. Compression moulded sheets of dimensions $2 \times 180 \times 180 \mathrm{~mm}^{3}$ were prepared using compression moulding machine (M/s. Boolani Engineering, Ltd Mumbai). The temperature of mold plate was maintained at $380{ }^{\circ} \mathrm{C}$ with cycle of time 15 mins, breathing was done after 5 mins with an interval of $1 \mathrm{~min}$ and then kept at $360^{\circ} \mathrm{C}$ constant temperature and pressure and subsequently cooled to $40{ }^{\circ} \mathrm{C}$ under continuous hydraulic pressure of $180 \mathrm{~kg} / \mathrm{cm}^{2}$. Test samples were prepared as per various ASTM standards.

\subsection{Mechanical Properties}

Uniaxial tensile testing was carried out using Universal Tensile Testing Machine(UTM) LR 50K (Lloyds Instrument Ltd. UK) at a cross head speed of $50 \mathrm{~mm} / \mathrm{min}$. Tests were conducted in accordance with ASTM D 638, taking specimens of dimensions $165 \times 13 \times 3 \mathrm{~mm}^{3}$. Corresponding Young's modulus and elongation at break were recorded. Flexural properties were measured using a three-point bending test method as per ASTMD 790, in the same universal testing machine. The test was carried out with rectangular bars of dimension $80 \times 12.7$ $\times 3 \mathrm{~mm}^{3}$ at a jaw speed of $0.8 \mathrm{~mm} / \mathrm{min}$ at room temperature. The compression molded samples of dimensions $127 \times 12.7 \times 3 \mathrm{~mm}^{3}$. A total of five specimens were tested for each sample at room temperature to obtain the average impact value. Charpy impact tests were performed using a $2.7 \mathrm{~J}$ pendulum and striking velocity of $3.46 \mathrm{~m}^{2} / \mathrm{s}$ on an Avery Denison Impact tester (model 6709), based on ASTM D 256-92.

\subsection{Limiting Oxygen Index (LOI)}

The LOI, (according to ASTM D2863-77) was measured using Dynisco Instrument (USA), with specimen dimensions $70 \times 6 \times 3 \mathrm{~mm}$. A total of five specimens were tested to obtain the average value of LOI. 


\subsection{Modulated Differential Scanning Calorimeter (MDSC)}

Glass transition temperature $\left(\mathrm{T}_{\mathrm{g}}\right)$, melting temperature $\left(\mathrm{T}_{\mathrm{m}}\right)$ and crystallization temperature $\left(\mathrm{T}_{\mathrm{c}}\right)$ of Polyetheretherketone mica and fly ash composites were studied using MDSC Q100 (TA, USA). Temperature calibration was performed using Indium as a reference $\left(\mathrm{T}_{\mathrm{m}}=156.60{ }^{\circ} \mathrm{C}\right.$ and Heat flow $=28.5 \mathrm{~J} / \mathrm{g}$ ). The heating rate of the samples was $20{ }^{\circ} \mathrm{C} / \mathrm{min}$ with sample weight between 7 to $9 \mathrm{mg}$ using standard aluminum sample pan. The experiments were carried out under nitrogen flow of $50 \mathrm{ml} / \mathrm{min}$ over a temperature range of $40-400{ }^{\circ} \mathrm{C}$.

\subsection{Dynamic Mechanical and Thermal Analysis (DMTA)}

DMTA was carried out in tension mode using GABO Qualimeter (Eplexor 150N, Germany) dynamic mechanical and thermal analyzer at a heating rate of $2{ }^{\circ} \mathrm{C} / \mathrm{min}$ and deformation frequency of $10 \mathrm{~Hz}$. The specimen size $50-40 \mathrm{~mm}$ in length, $5-4 \mathrm{~mm}$ in width and $3 \mathrm{~mm}$ thickness were cut from the molded sheet. The DMTA test was carried out from the temperature range 50 to $250{ }^{\circ} \mathrm{C}$ under the static load of $50 \mathrm{~N}$ and dynamic load of $40 \mathrm{~N}$. Before starting the cycle, the specimen was held for $5 \mathrm{~min}$ at $40{ }^{\circ} \mathrm{C}$ to stabilize the position of the clamped.

\subsection{Scanning Electron Microscopy (SEM)}

SEM studies of fractured surface of tensile sample were carried out on Jeol (6380LA, Japan). Samples were sputter coated with gold to increase surface conductivity. The digitized images were recorded.

\section{RESULTS AND DISCUSSION}

\subsection{Mechanical Properties}

Tensile strength of Polyetheretherketone composite initially increased with the content of fillers as shown in Fig 1, after reaching a maximum value at $20 \mathrm{wt} \%$ filler (fly ash and mica) and then decreased. The increment in tensile strength of PEEK mica composites were due to the platy structure of mica filler producing good reinforcement. Tensile strength of PEEK fly ash composites were gradually increased with the addition of fly ash up to $20 \mathrm{wt} \%$. Comparing the tensile properties of PEEK mica composites with that of PEEK fly ash composites, the later system provided slightly lower improvement in the tensile strength which is probably due to spherical shape of the fly ash particles. The effect of filler on tensile strength may be due to the counterbalance of two phenomenons; with the increase in the filler content in a polymer composite there is increase in effective surface fracture energy, size of voids and agglomeration of filler particles. The dispersed particles make the crack propagation path longer, absorb a 
portion of energy and enhance the plastic deformation. Therefore, the surface fracture energy increases and the strength of composites increase with volume percentage of filler. However, with increase in mica content, the size of voids formed when the polymer matrix detaches from the filler particles became critically large and initiates the main crack [9]. In addition, the inevitably increased agglomeration of dispersed filler particles resulted in decreased mechanical strength due to the lower strength of the agglomerates themselves [10].

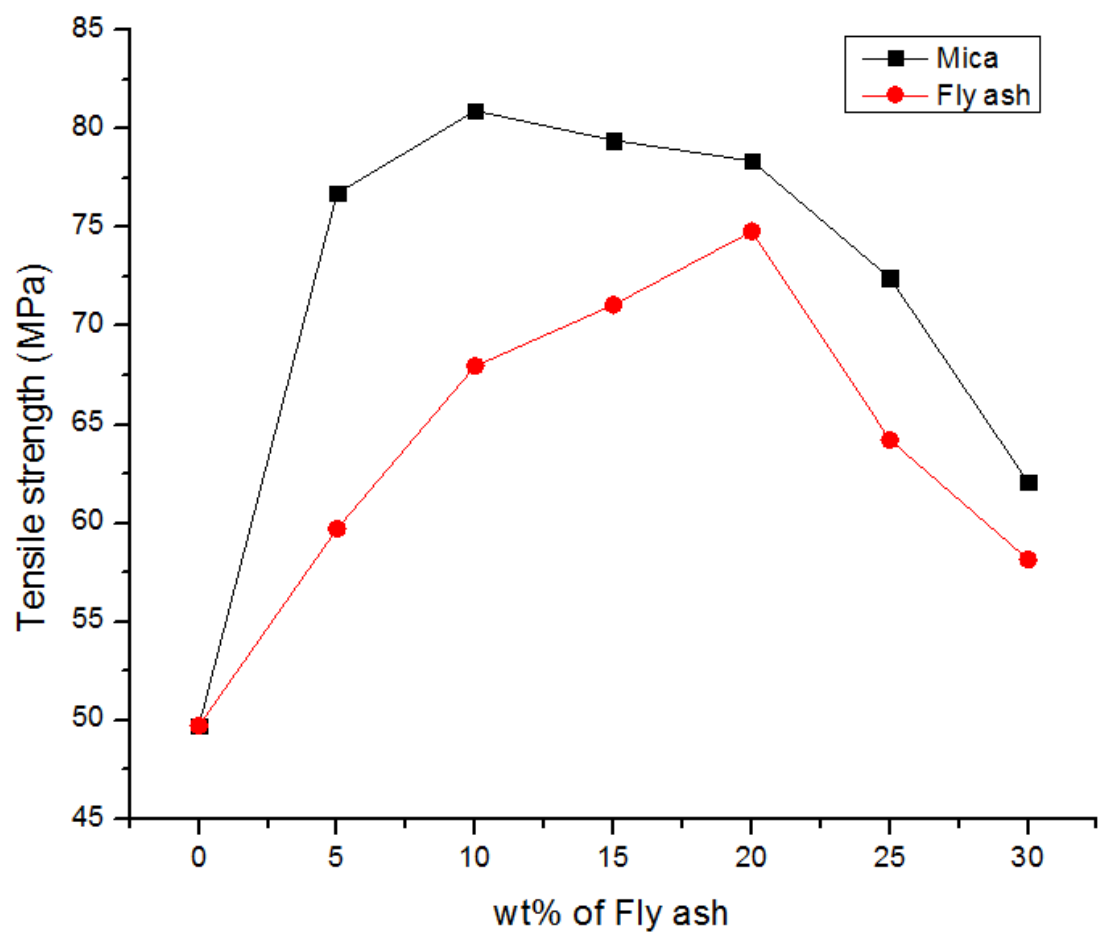

Figure 1. Tensile strength of PEEK mica and fly ash composites.

Tensile modulus of Polyetheretherketone filled composites increased rapidly with the content of filler as shown in Fig 2.The tensile modulus increases with incorporation of filler in the polymer matrix. The increase in the tensile modulus of PEEK fly ash composite is due to the increase in the crystallinity of composites by addition of fly ash. In case of PEEK mica composite, tensile modulus was increased continuously with increase in the wt $\%$ of mica. The variation in the rate of change of increase in tensile modulus indicates that effect of extent of hydrogen bonding as well as intermolecular interaction of matrix and filler.

Elongation at break of PEEK filled composites decreased with increase in filler content for both fly ash and mica as shown in Fig 3. The rate of decrease in elongation at break of PEEK fly ash composites were higher than the PEEK mica composites shows that the brittleness of composite increases with the fly ash content. The mica particles give the reinforcement effect due to its platy structure. Also the toughness decreased with increasing fly ash content [6]. Such a significant drop could be due to the agglomeration of fly ash which acts as the crack initiation 
point; this is in agreement with the general trend that elongation decreases with increase in filler content [11].

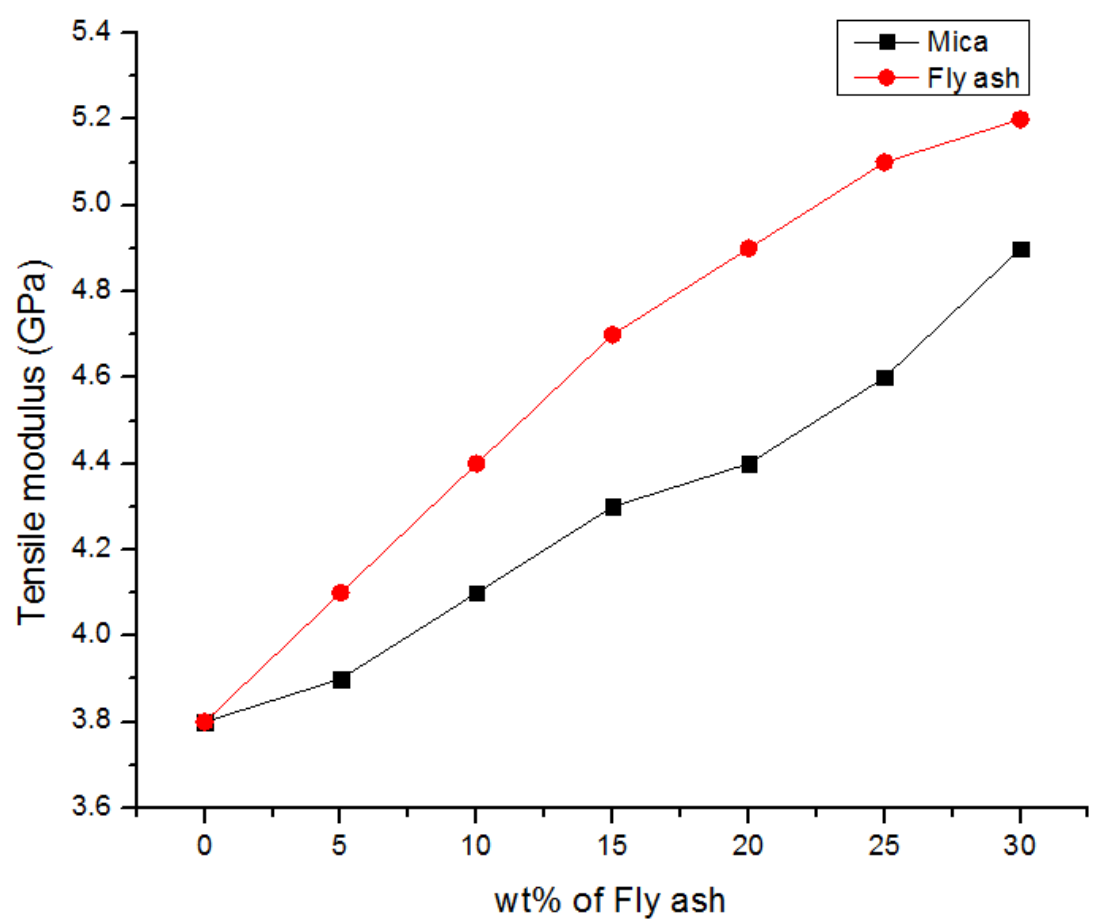

Figure 2. Tensile modulus of PEEK mica and fly ash composites.

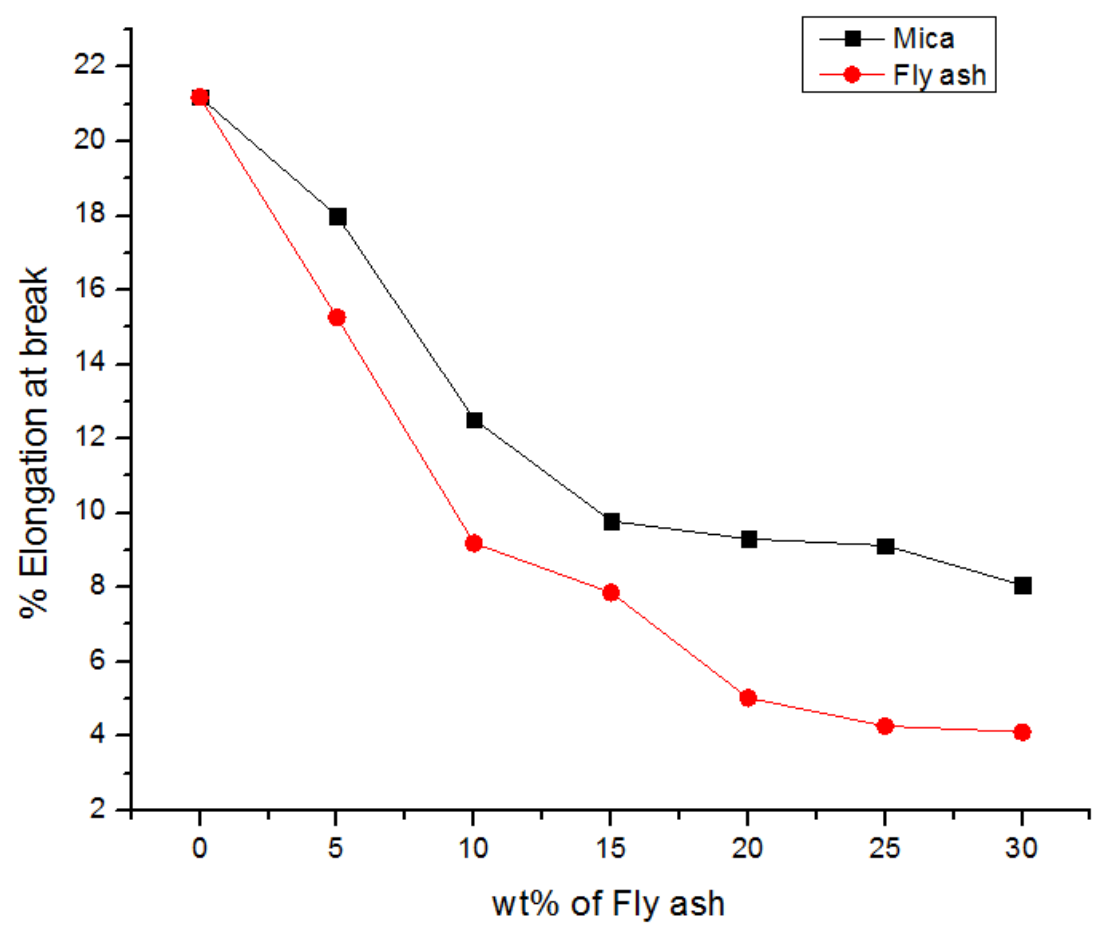

Figure 3. Elongation at break of PEEK mica and fly ash composites. 
Flexural modulus of filled Polyetheretherketone composites increased as the concentration of fillers increased, as shown in Fig 4. In PEEK fly ash composites, flexural modulus increased up to $20 \mathrm{wt} \%$ and then dropped due to higher loading of fly ash indicating agglomeration. It is well known that the modulus of a filled system depends on the properties of components, fillers and matrix; the modulus of fly ash is higher than that of the matrix, and the flexural moduli of filled composites are higher than that of polymer resin. Flexural modulus of PEEK also increased continuously by the addition of mica. Flexural strength of mica filled Polyetheretherketone composites increased up to $20 \mathrm{wt} \%$ of mica. Fig 5 shows the flexural strength of PEEK mica and fly ash composites. In case of fly ash the flexural strength was increases up to $20 \mathrm{wt} \%$ but thereafter decreased.

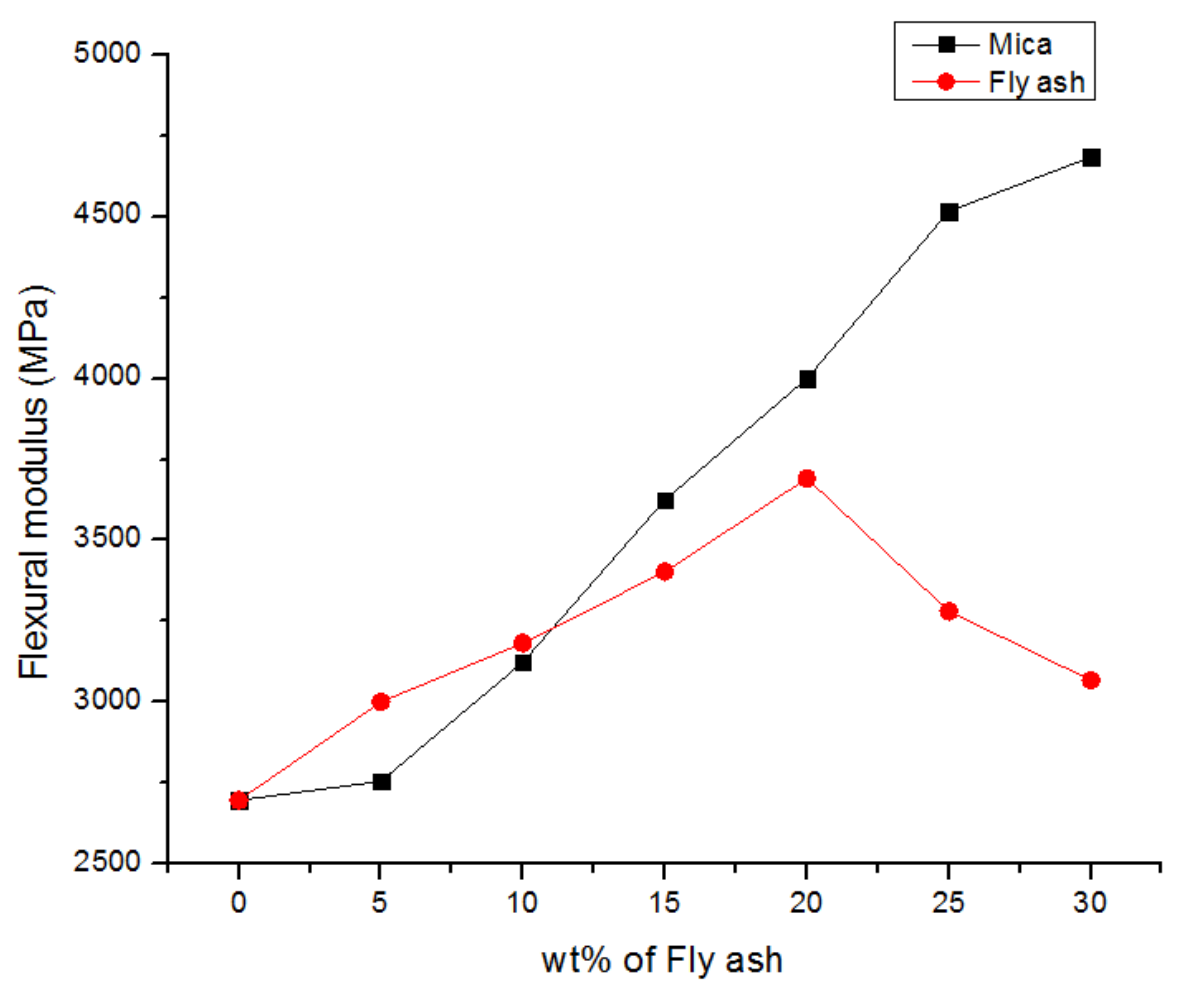

Figure 4. Flexural modulus of PEEK mica and fly ash composites.

Charpy impact test is a high speed fracture test that measures the energy to break the specimen under banding condition. The specimen is deformed within a short time and therefore exposed to high strain. The reinforcement seems to be very effective up to $15 \mathrm{wt} \%$ of mica since the Charpy impact strength increased. The impact strength had a sudden drop after $15 \mathrm{wt} \%$ of mica as shown in Fig 6. From the figure it can be noted that the Charpy impact strength of all composites of PEEK fly ash are lower than that of virgin PEEK. Fly ash leads to easy crack initiation along with more brittle nature of composites. The increase in toughness may be caused by the inhomogeneous particle shape and size of micro particles. Since the edges of mica particles have different angularities and they would facilitate failure under impact condition due to localized stress concentrations. 


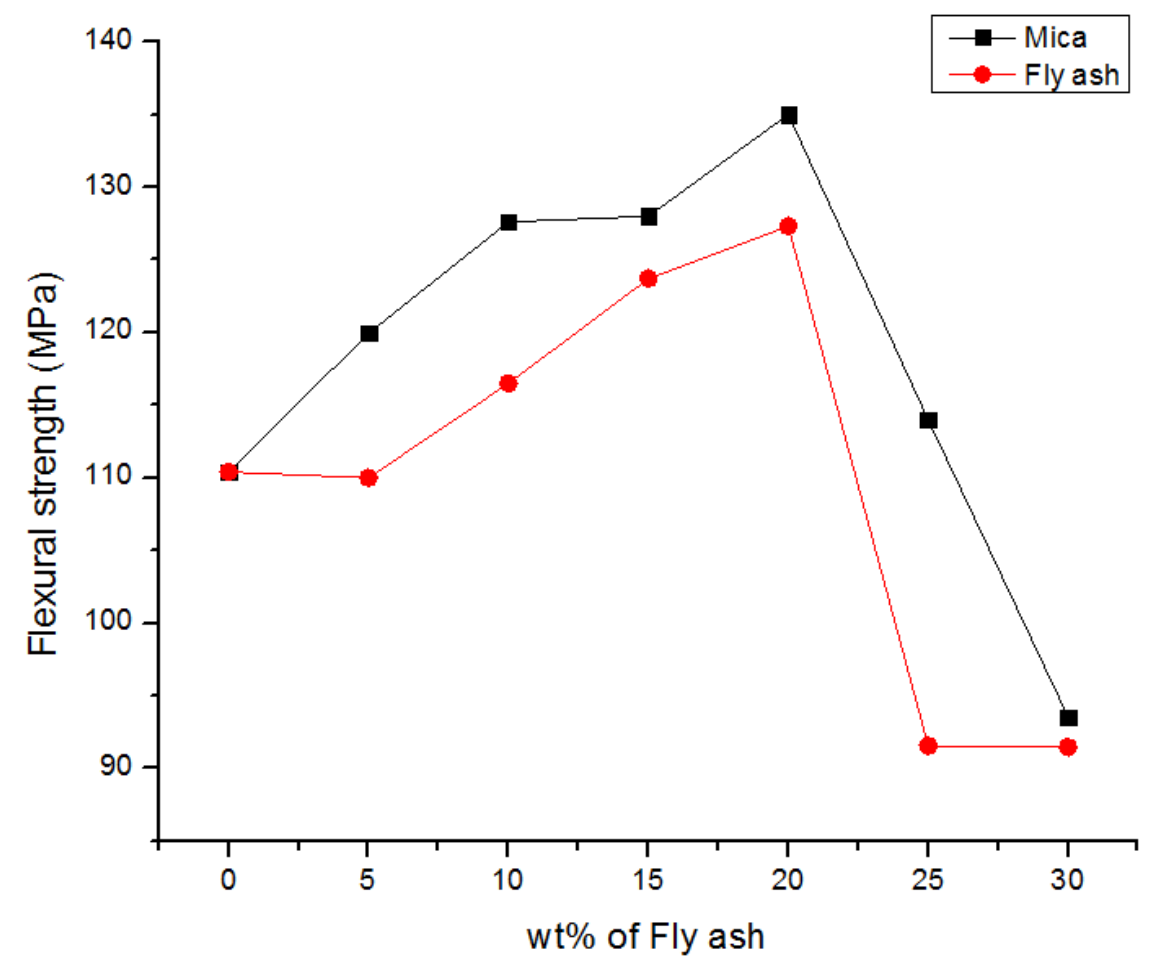

Figure 5. Flexural strength of PEEK mica and fly ash composites.

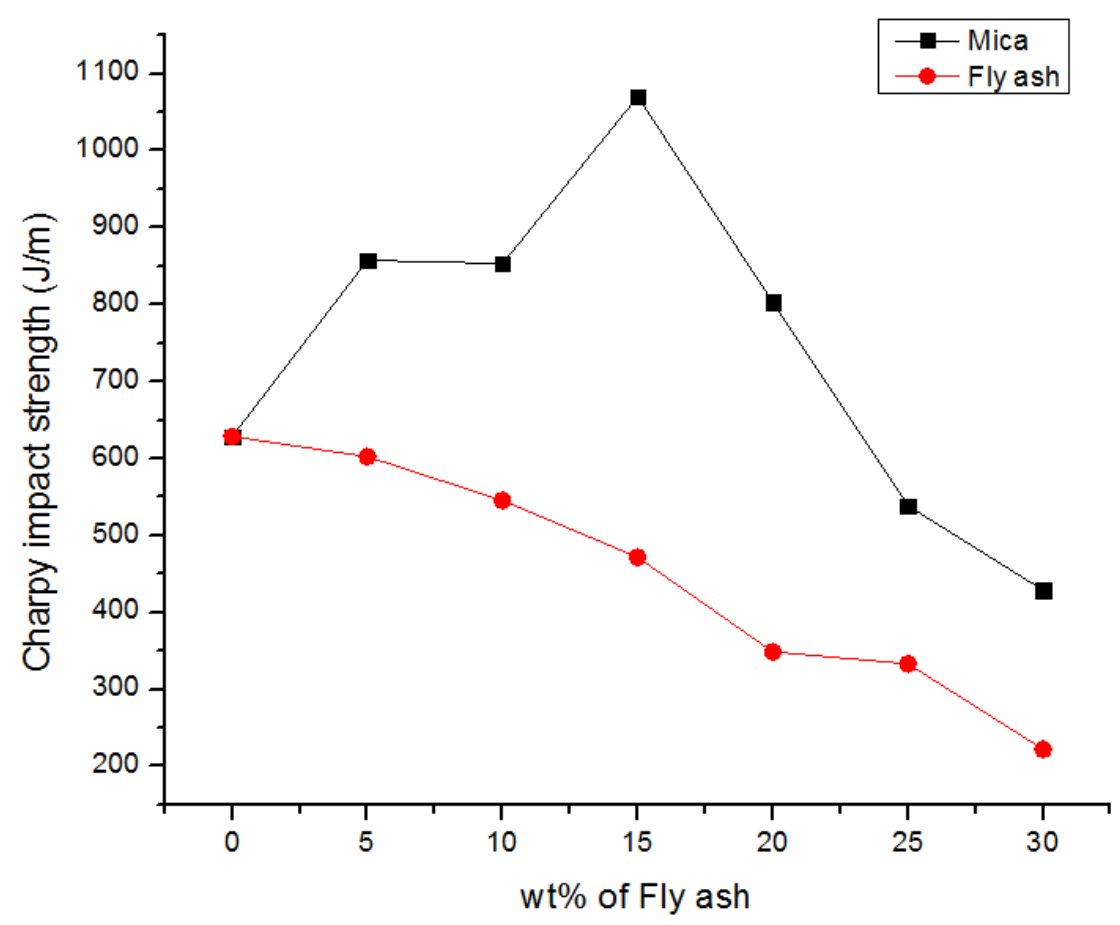

Figure 6. Charpy impact strength of PEEK mica and fly ash composites. 


\subsection{Limiting Oxygen Index (LOI)}

The LOI is the minimum percentage of oxygen in an oxygen-nitrogen mixture that will initiate and support burning for three minutes [12]. The LOI increased by $24 \%$ with addition of $30 \mathrm{wt} \%$ of mica in PEEK and in case of fly ash the LOI increased by $11 \%$ with $30 \mathrm{wt} \%$ of fly ash loading therefore the fillers reduced flammability of composites as shown in Fig 7. This behavior is due to the accumulation of silicate on the surface of the burning specimen which creates a proactive barrier to heat and mass transfer.

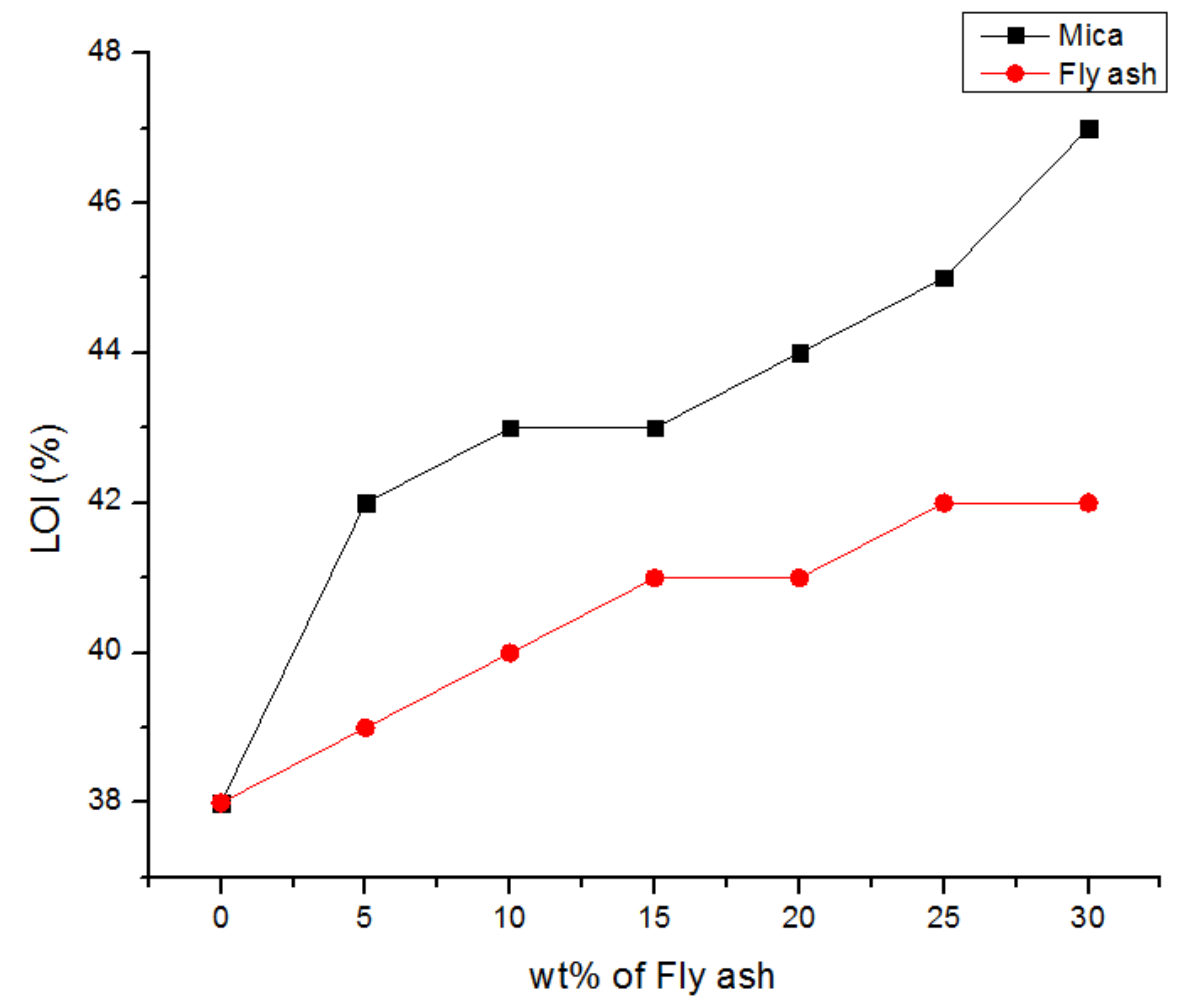

Figure 7. Limiting oxygen index of PEEK mica and fly ash composite.

\subsection{Modulated Differential Scanning Calorimeter (MDSC)}

The non-isothermal crystallization behavior of the PEEK mica composites were studied by MDSC with the sample cooled from 400 to $40{ }^{\circ} \mathrm{C}$ at constant a cooling rate $20{ }^{\circ} \mathrm{C} / \mathrm{min}$. Fig 8 shows that there is no significant change in the melting points $\left(\mathrm{T}_{\mathrm{m}}\right)$ of both filled and unfilled samples of mica and fly ash PEEK composites. The melting temperature are consistently scattered within the typical range of $330-385{ }^{\circ} \mathrm{C}$ for PEEK resin. MDSC thermogroms obtained for PEEK mica and fly ash composites sample shows the glass transition, exothermic crystallization peak and the endothermic peak of crystalline phase melting. By measuring these peak areas, it is possible to determine the volume fraction crystallinity of matrix [13]. 


$$
X_{v}=\frac{\left(H_{m}-H_{c}\right) \rho_{a}}{H_{f}\left(1-X_{m s}\right) \rho_{c}-\left(H_{m}-H_{c}\right)\left(\rho_{c}-\rho_{a}\right)}
$$

$\mathbf{X v}=$ Volume fraction crystallinity.

$\mathbf{H}_{\mathbf{m}}=$ heat of fusion measured as the area of melting peak.

$\mathbf{H}_{\mathbf{c}}=$ heat of additional crystallization measured as the area under the crystallization peak.

$\mathbf{H}_{\mathbf{f}}=$ theoretical heat of fusion for a pure crystalline phase for PEEK $130 \mathrm{~J} / \mathrm{g}$.

$\boldsymbol{\rho}_{\mathrm{a}}=$ density of amorphous phase for PEEK $1.2626 \mathrm{~g} / \mathrm{cm}^{3}$

$\boldsymbol{\rho}_{\mathbf{c}}=$ density of crystalline phase for PEEK $1.4006 \mathrm{~g} / \mathrm{cm}^{3}$

$\mathbf{X}_{\mathbf{m s}}=$ mass fraction of reinforcement.

The $\mathrm{X}_{\mathrm{V}}$ value for composites filled with same amount of mica and fly ash are as shown in Table 1. This might be due to lower degree of obstruction from the finer particles for the extension of PEEK crystalline segments. The increase in perfection or crystallinity is due to enhanced crystal nucleation in the region surrounding the reinforced particles [14, 15]. The higher percentage crystallinity for $20 \mathrm{wt} \%$ of $44 \mu \mathrm{m}$ size mica PEEK composite shows improved interaction between PEEK and mica particles. In case of PEEK fly ash degree of crystallinity continuously increases by addition of fly ash as shown in Fig 8 . The $T_{g}$ and $T_{m}$ of PEEK composites were not much affected by the fillers but crystallization temperature increased at low concentration (10 wt $\%$ ) of fly ash and mica and then decreased as shown in Fig 9.

Table1. PEEK filled fly ash and mica of $\mathrm{H}_{\mathrm{m}}, \mathrm{H}_{\mathrm{c}}$ and $\%$ crystallinity $\left(\mathrm{X}_{\mathrm{v}}\right)$

\begin{tabular}{cccc}
\hline Materials & $\mathbf{H}_{\mathbf{m}} \mathbf{( J / g )}$ & $\mathbf{- H}_{\mathbf{c}} \mathbf{( J / g )}$ & $\mathbf{X}_{\mathbf{v}}(\mathbf{\%})$ \\
\hline VPEEK & 16.79 & 37.20 & 39.04 \\
10FA44* & 19.37 & 28.81 & 38.70 \\
20FA44 & 22.65 & 27.79 & 45.93 \\
30FA44 & 21.97 & 25.43 & 49.51 \\
10M44** & 22.35 & 28.44 & 40.06 \\
20M44 & 21.71 & 27.07 & 44.34 \\
30M44 & 14.82 & 18.84 & 34.61 \\
\hline
\end{tabular}

$* 10 \mathrm{wt} \%$ fly ash $44 \mu \mathrm{m}$ filled PEEK composite, $* * 10 \mathrm{wt} \%$ mica of $44 \mu$ filled PEEK composite. Similarly 20, 30 withstand $20 \%$ and $30 \%$ fly ash and mica 


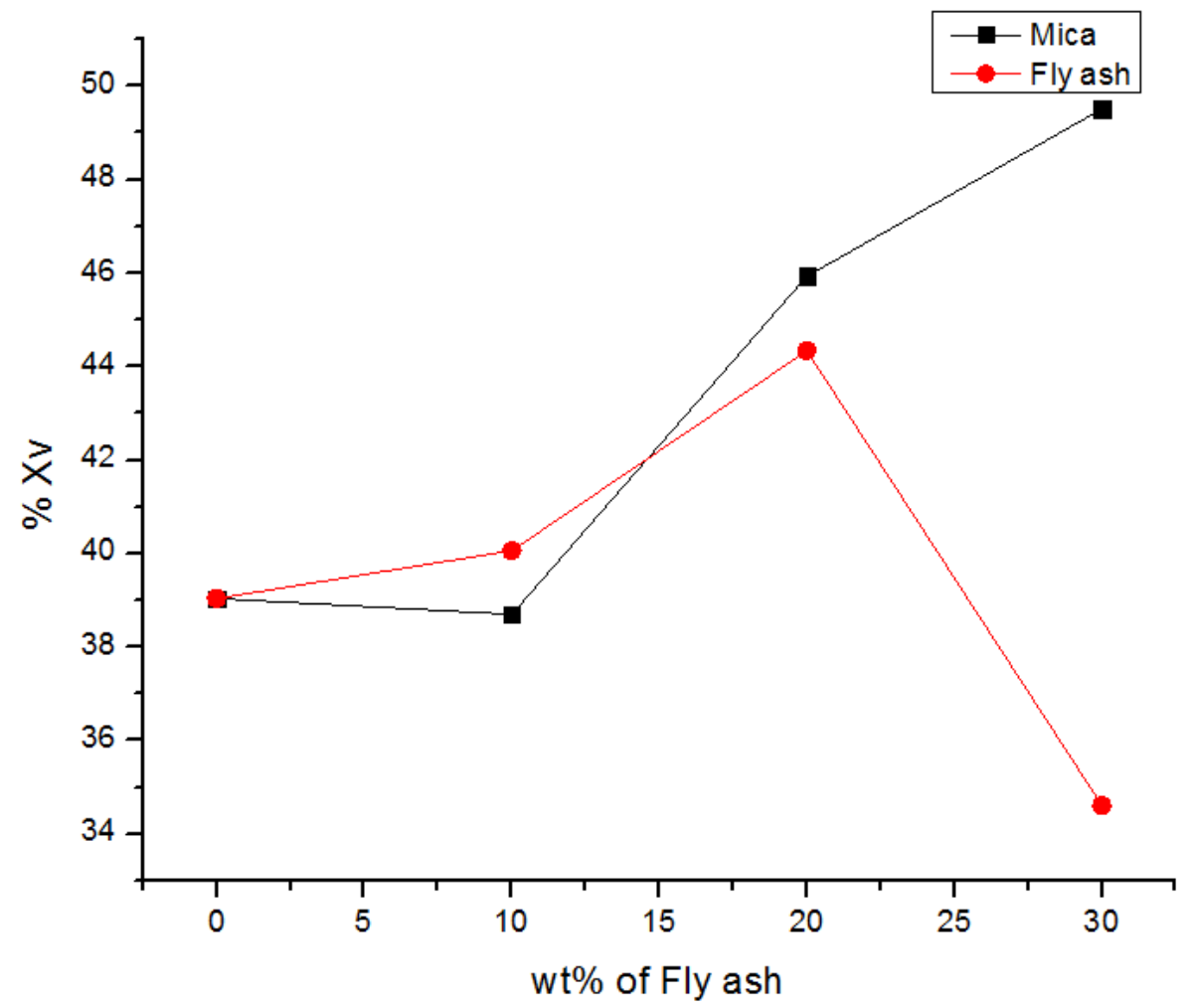

Figure 8. Degree of crystallinity of PEEK mica and fly ash composites.

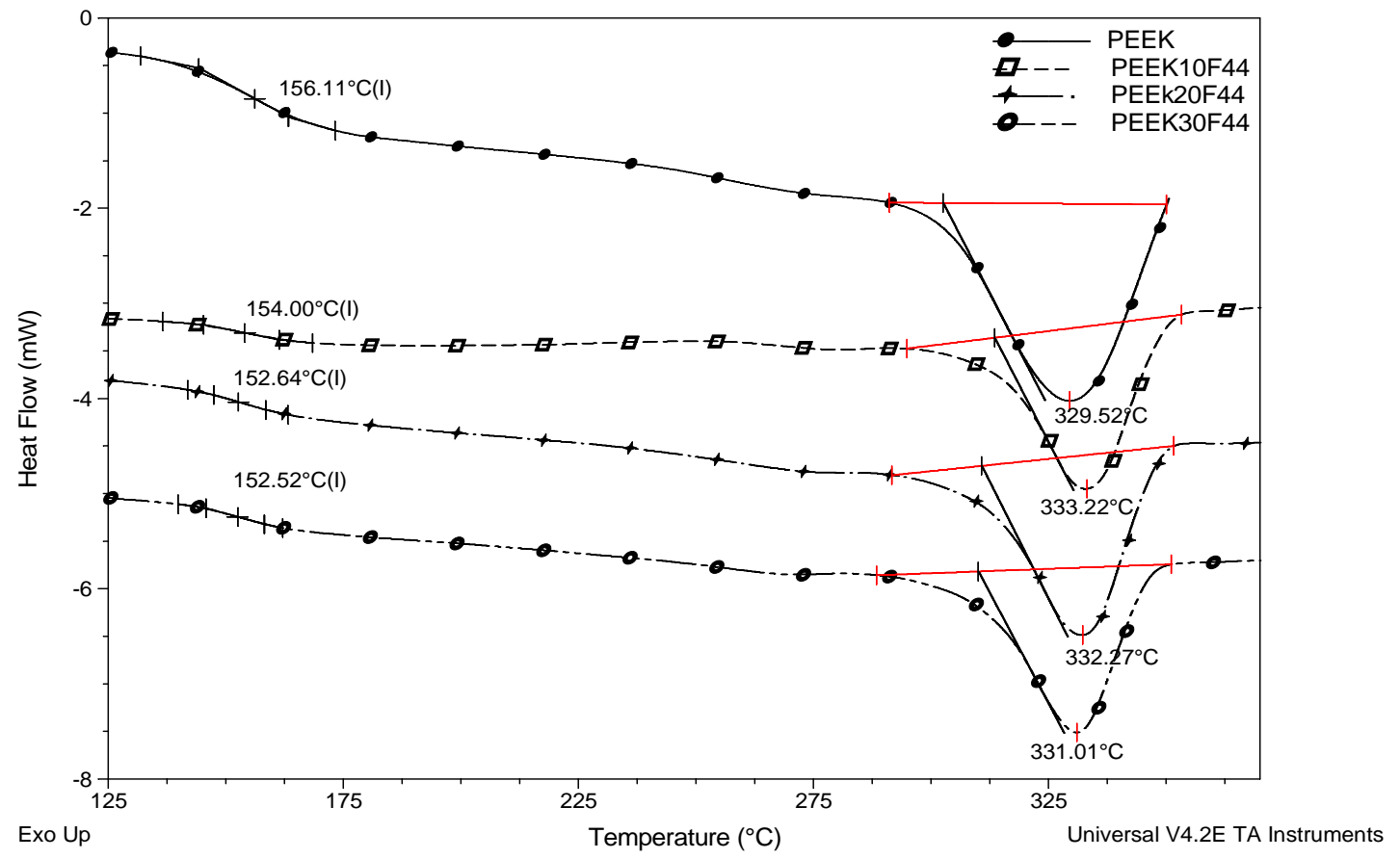

(a) 


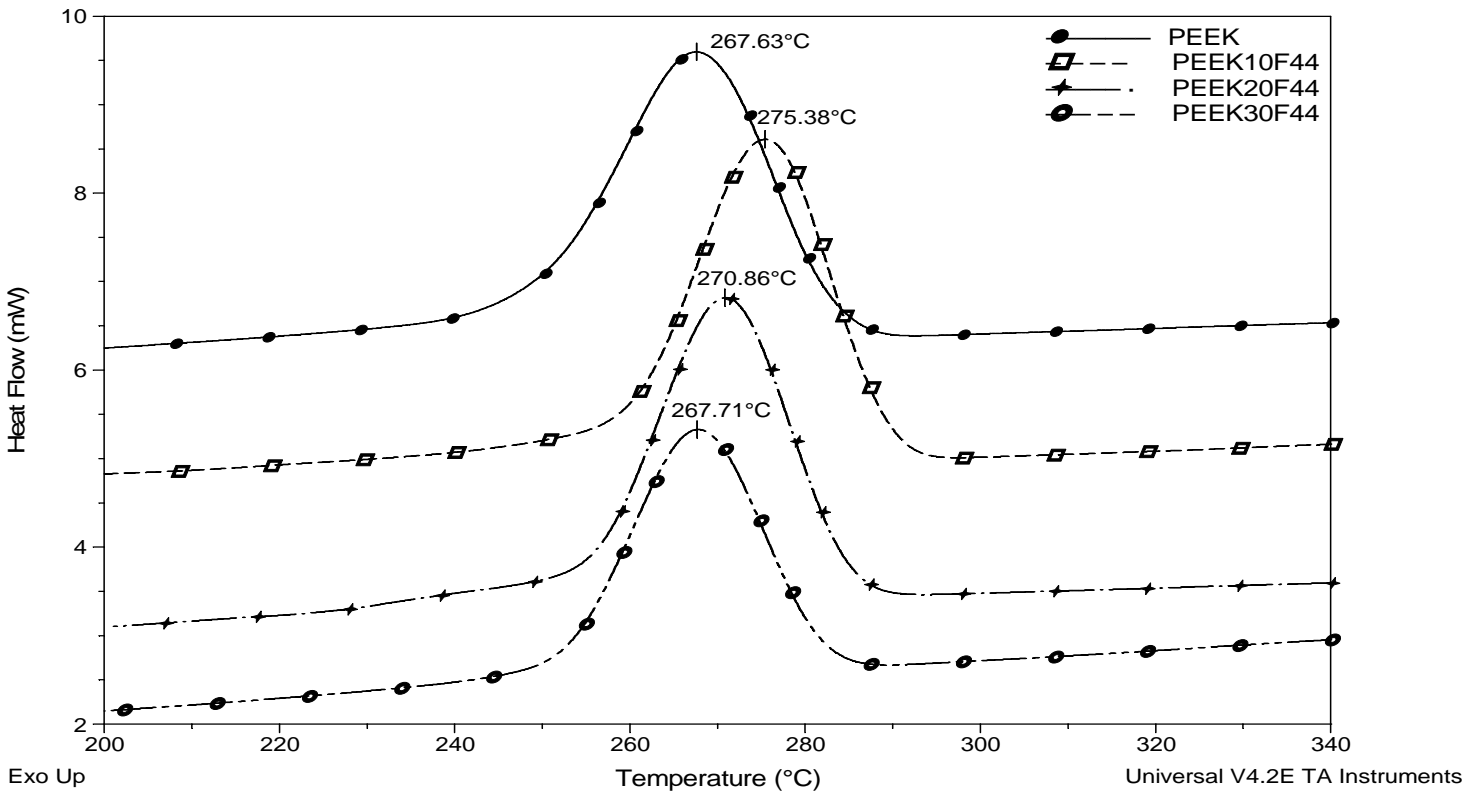

(b)

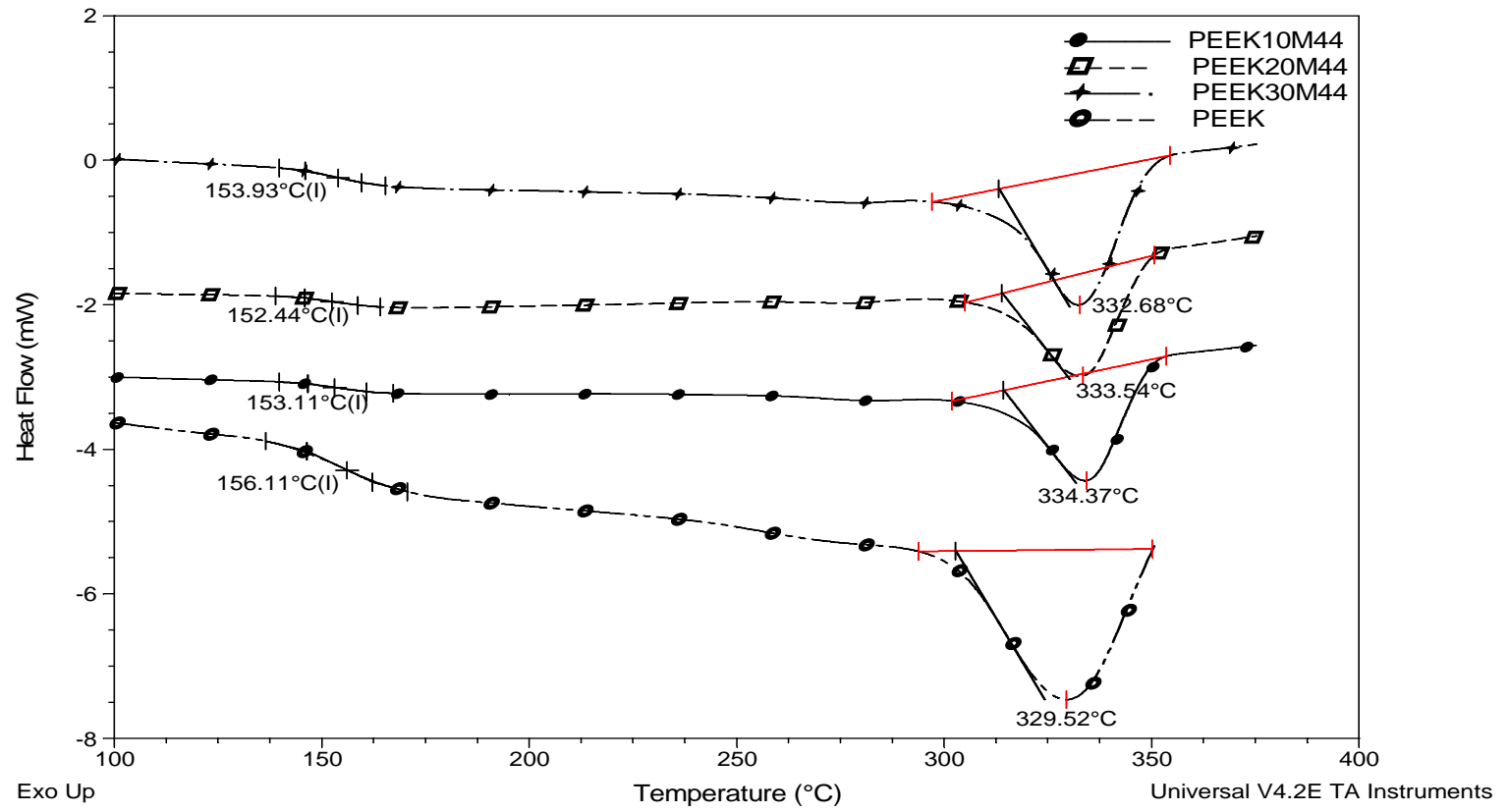

(c) 


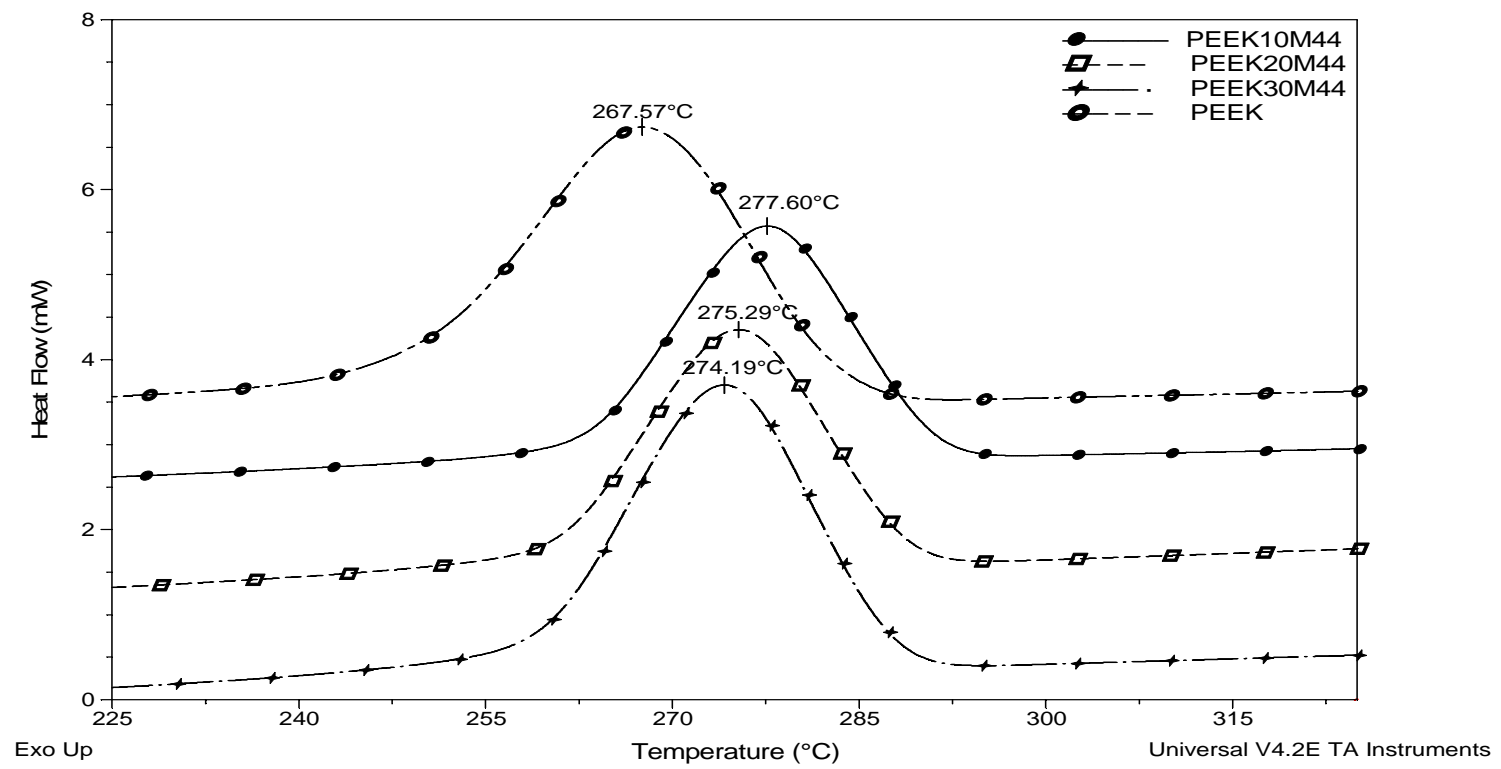

(d)

Figure 9. Modulated differential scanning calorimeter (MDSC) thermograms for (a) and (c) second heating curves of $\mathrm{T}_{\mathrm{g}}$ and $\mathrm{Tm}$ of $44 \mu \mathrm{m}$ mica filled PEEK composites. (b) and (d) cooling curves of crystallization temperature Tc of $44 \mu \mathrm{m}$ mica filled PEEK composites.

\subsection{Dynamic Mechanical and Thermal Analysis (DMTA)}

Fig 10 (a) shows E' versus the temperature for PEEK reinforced with 0-30 wt \% mica. As expected, E' increased with an increase in mica in the PEEK matrix. The reinforcing effect of mica was more intense above $T_{g}$. This was similar to a previous study of AlN/PEEK [16] and reported VGCF/PEEK composites, for which the modulus increased with the filler content. However, this was in contrast to a short-carbon-fiber-reinforced/poly(ether ether ketone) (SCFRPEEK) composite, for which an intense increase in the modulus was observed below $\mathrm{Tg}$, and afterwards, it decreased rapidly as in pure PEEK [17]. The modulus of PEEK mica composites, especially at low temperature, is affected by the content of mica used. At $50{ }^{\circ} \mathrm{C}$ temperature the $\mathrm{E}^{\prime}$ of mica filled PEEK composites increases as concentration of mica increased. This indicates that incorporation of mica filler improved the stiffness of the composite and the dependence of $E^{\prime}$ on filler loading is more pronounced around the glassy region. The drop in storage modulus with temperature during the transition from glassy to rubbery state occurred around temperature 150 ${ }^{\circ} \mathrm{C}$ for all the specimens. The glass transition temperatures according to storage modulus were negligibly affected by mica loading in PEEK. The storage modulus of PEEK filled $20 \mathrm{wt} \%$ composites is increased by $61 \%$ as compared to pure PEEK at $50{ }^{\circ} \mathrm{C}$. The modulus increased due to high modulus of mica and due to good interaction between the mica and the matrix, which restricts the segmental motion of the PEEK molecules. These results indicted an effective 
transfer of load from the matrix to mica. In this study, the significant improvement in E' might be attributed to the uniformly dispersed mica particles in the matrix, which increased the interfacial area between mica and the PEEK matrix. Fig 10 (b) shows the temperature dependences of the storage modulus of PEEK composites with fly ash loading of $0-30 \mathrm{wt} \%$. The $\mathrm{E}^{\prime}$ have improve $143 \%$ at $30 \mathrm{wt} \%$ fly ash of temperature $200{ }^{\circ} \mathrm{C}$ compared to pure PEEK, inclusion of fly ash in PEEK increase the high temperature performance of PEEK composites.
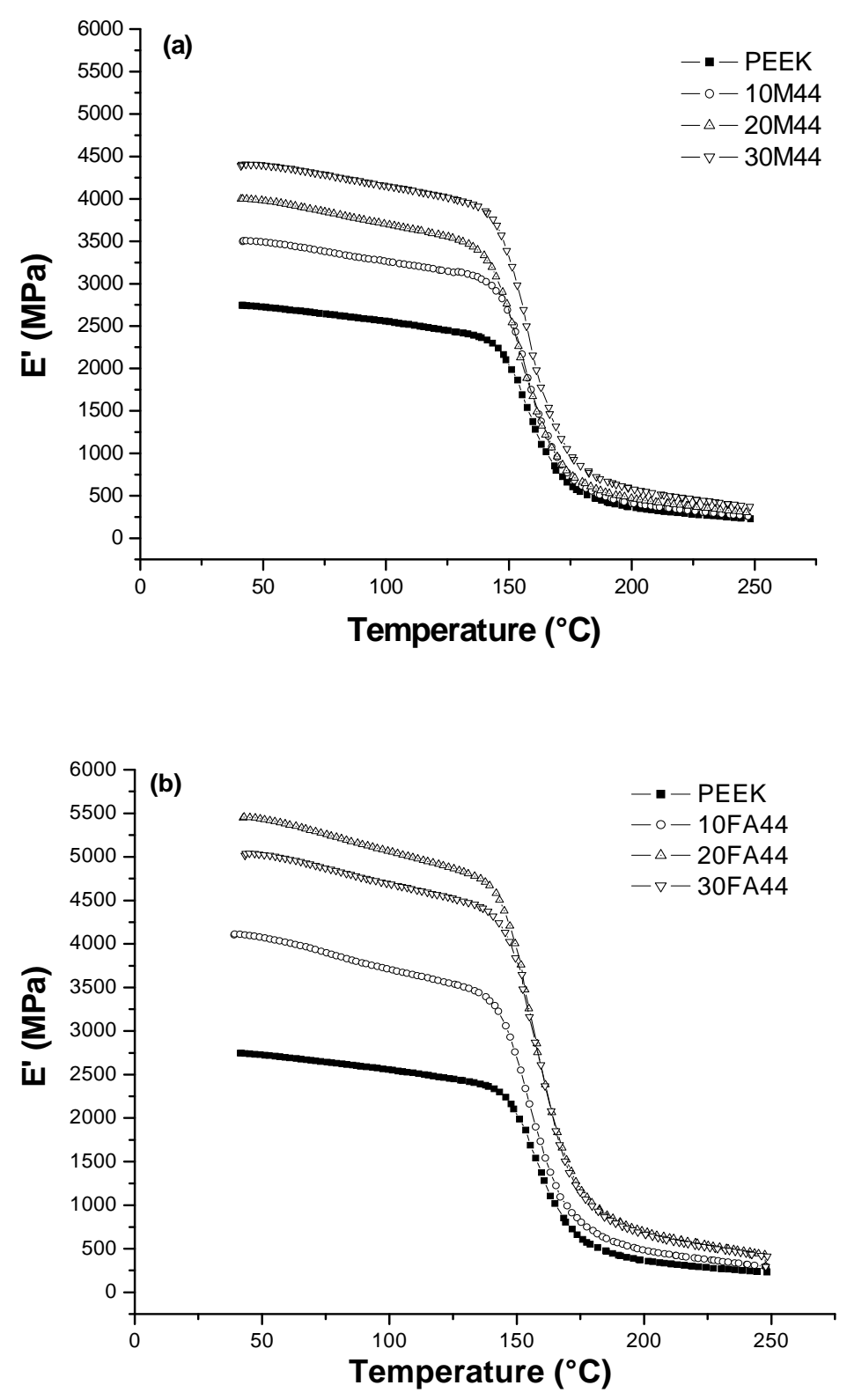

Figure 10. Dynamic mechanical spectrum of storage modulus of (a) PEEK mica composites and (b) PEEK fly ash composites. 


\subsection{Scanning Electron Microscopy (SEM)}

The morphological and particle distribution in PEEK mica and fly ash composites were studied using SEM. Fig 11 (a) displays the micrograph of PEEK mica and (b) PEEK fly ash particles respectively. It is evident that the mica particles are uniformly dispersed within the PEEK matrix and no aggregates of filler particles are observed. This further corroborates that the composite with $20 \mathrm{wt} \%$ mica produced relatively improved properties than PEEK fly ash composites. The micrograph also shows that the mica particles were more reinforced than fly ash particles in PEEK matrix.

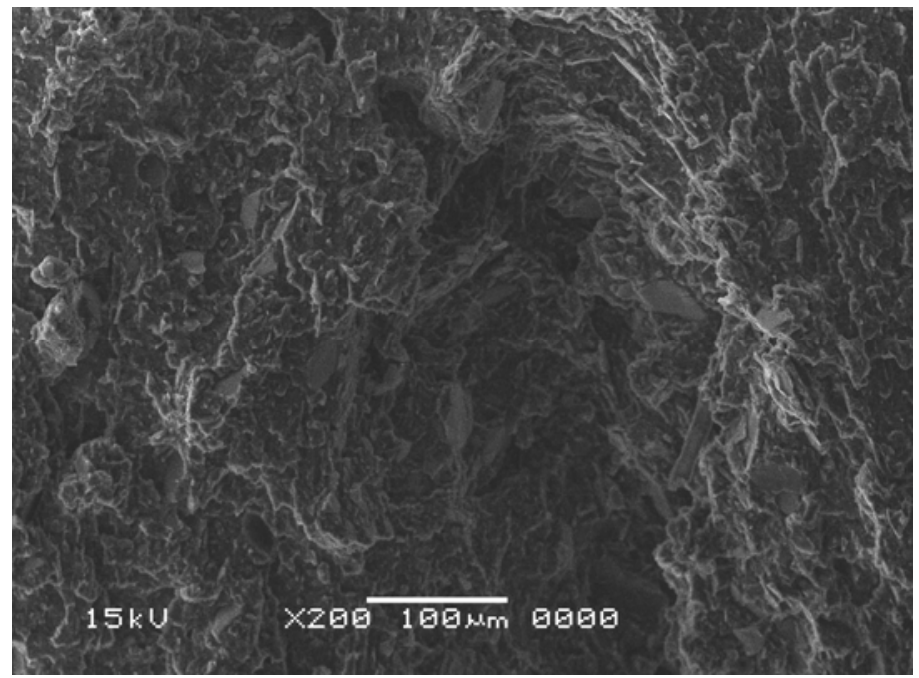

(a)

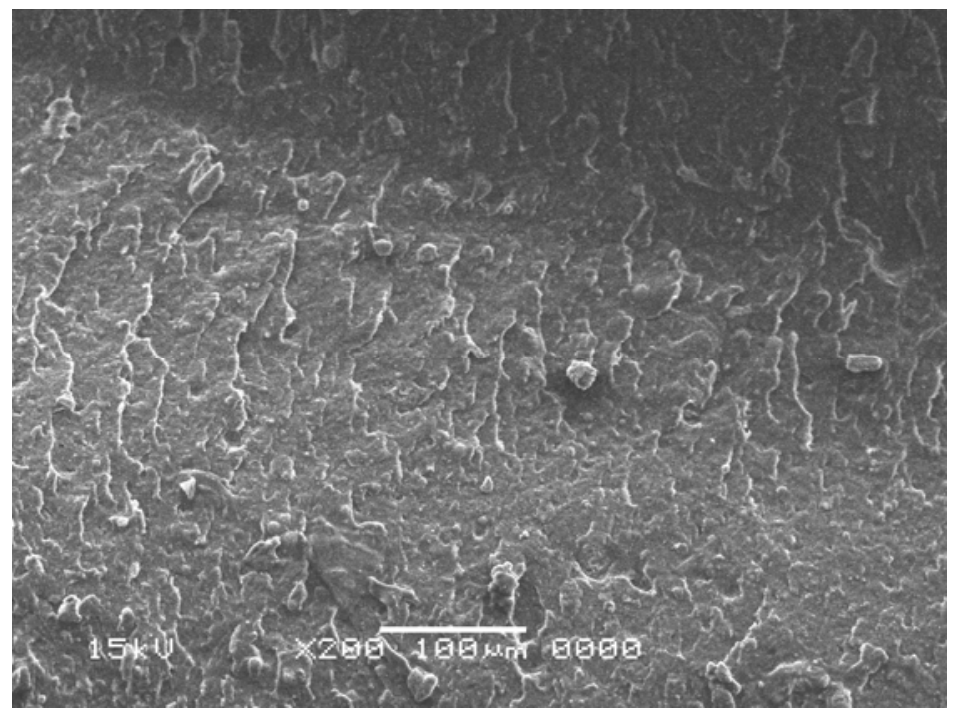

(b)

Figure 11. SEM image of (a) $20 \mathrm{wt} \%$ mica of $44 \mu \mathrm{m}$ filled PEEK composite, (b) $20 \mathrm{wt} \%$ fly as of $44 \mu \mathrm{m}$ filled PEEK composite. 


\section{CONCLUSIONS}

The following conclusions have been drawn from the present study.

Tensile modulus of PEEK fly ash and mica composites were improved by the incorporation of 5$30 \mathrm{wt} \%$ filler. The fly ash filled PEEK composites showed higher tensile modulus than mica. The optimum strength improvement occurred in composition of $20 \mathrm{wt} \%$ fly ash and mica filled PEEK. With greater amount of fillers (30 wt \%), the tensile and flexural strength decreased, whereas the tensile modulus increased consistently with the incorporation of fillers. Charpy impact strength also improved by using mica in PEEK composites but in case of fly ash impact strength was decreased. PEEK filled by fly ash and mica showed remarkable improvement in limiting oxygen index. LOI of PEEK mica was higher than PEEK fly ash composites. In overall performance mica showed better reinforcement properties than fly ash.

\section{REFERENCES}

[1] Selley, J., 1988, Encyclopedia of polymer science and engineering, Vol.1, Wiley, New York, pp. 816 - 954.

[2] Leidner, J., Woodhams, R. T., 1974, “The strength of polymeric composites containing spherical fillers.” J. Appl Polym. Sci, Vol. 18, pp. 1639-1654.

[3] George, W., 1999, Mica, Handbook of Fillers, Vol. 1, ed. 2, , Toronto, New York, Chem Tech Publishing, pp. $112-115$.

[4] Goyal, R. K., Tiwari, A. N., Negi, Y. S., 2005, "Preparation of high performance composites based on AlN/poly(ether ether ketone) and their properties" Eur. Polym. J., Vol. 41, pp. 2034-2044.

[5] Goyal, R. K., Tiwari, A. N., Negi. Y. S., 2007, "Dynamic mechanical properties of $\mathrm{Al}_{2} \mathrm{O}_{3} /$ poly(ether ether ketone) composites" J. Appl Polym. Sci, Vol. 104, pp. $568-575$.

[6] Sarajaadevi, M., Murugesan, V., Rengaraj, K., Anamd, P., 1998, "Utilization of flyash as filler for unsaturated polyester resin” J. Appl Polym. Sci, Vol. 69, pp. 1385 - 1391.

[7] Katz, H.S., Milevski, J.V., 1978, Handbook of Fillers and Reinforcements for Plastics, Vol.1, ed.1, Van Notrand Reinhold, New York, pp. 333 - 457 .

[8] Sheppherd, P. D., Golemba, F.J., Maine, F.W., 1978, In Handbook of fillers and Reinforcement for plastic, Van Nostrond Reinhold, New York. pp. $281-342$.

[9] Nielsen, L.E., 1974, Mechanical properties of polymers and composites, vol. 1, Marcel Dekker, New York. pp. 254 - 385.

[10] Zhou B, Ji.X., Sheng, Y., Wang, L., Jiang, Z., 2004, "Mechanical and thermal properties of poly(ether ether ketone) reinforced with $\mathrm{CaCO}_{3}$ ” Eur. Polym J., Vol. 40, pp. 2357 - 2363.

[11] Guhanathan, S., Saaraja, Devi. M., 2004, "Studies on interface in polyester/fly-ash particulate composites" J Composite Interfaces, Vol. 11, pp. 43 - 66. 
[12] Molcolm, P. Stevens., 1990, Polymer chemistry an introduction, Ed. 2, , Oxford university press, New York, pp. $174-75$.

[13] Ostberg, G. M. K., Seferis, J. C., 1987, “Annealing effects on the crystallinity of polyetheretherketone (PEEK)” J of Appl. Polym. Sci., Vol. 33, pp. 29 - 39.

[14] Baker, M.S.A., Cheang, P., Khor, K.A., 1999, "Thermal processing of hydroxyapatite reinforced poly(ether ether ketone) composites" J. Mater Process Technol., Vol. 89-90, pp. $462-466$.

[15] Goyal, R.K., Tiwari, A.N., Mulik, U.P., Negi, Y.S., "Effect of AlN on thermo mechanical properties of high performance poly(ether ether ketone)" J. Composites Part A, in press.

[16] Zhou, B., Ji, X., Sheng, Y., Wang, L., Jiang, Z., 2004, "Mechanical and thermal properties of poly(ether ether ketone) reinforced with $\mathrm{CaCO}_{3}$ " Eur. Polym. J., Vol. 40, pp. $2357-$ 2363.

[17] Kubat, J., Rigdahl, M., Welander, M., 1990, "Characterization of interfacial interactions in high density polyethylene filled with glass spheres using dynamic-mechanical analysis" $J$. Appl. Polym. Sci, Vol. 39, pp.1527 - 1539. 